\title{
A Relationship between Body Fat and Plasma Pseudo-cholinesterase
}

\author{
By W. T. C. BERRY AND P. J. COWIN \\ Ministry of Health, 23 Savile Row, London, W. I \\ AND D. R. DAVIES \\ Chemical Defence Experimental Establishment, Ministry of Supply, Porton, Wiltshire
}

(Received 6 May 1953)

The aim of this study was to determine whether there was any relationship between body fat and pseudo- (or plasma) cholinesterase. Hutchinson, McCance \& Widdowson (I95I), in reporting their studies of undernutrition and feeding, pointed out that, at the end of rehabilitation when men became 'fat', the average pseudo-cholinesterase was higher than normal. It therefore seemed of interest to investigate the relationship of body fat to pseudo-cholinesterase in men in metabolic equilibrium as opposed to that in men at the end of a dynamic process of equilibrium.

\section{METHODS}

Assessment of body fat. Brožek \& Keys (1950-I) have shown that there is a close correlation between the thickness of a layer of skin and subcutaneous fat at certain sites on the body and the proportion of body fat as determined by specific-gravity methods. We have used five sites for measurement; the front and back of the arm, the subcostal, the subscapular and subumbilical regions. Details of these sites have been given elsewhere (Berry \& Cowin 195I). Edwards (1950) has produced evidence to show that fluctuations in obesity are reflected in changes in skinfold thickness, and these, in most parts of the body are in proportion with one another.

The sum of the five measurements was therefore used as a measure of leannessfatness.

The estimation of pseudo-cholinesterase activity. Blood specimens were collected on filter-paper by a method which will be described in full elsewhere by Ainsworth, Davies \& Rutland. The procedure was as follows. The finger to be punctured was first carefully washed to remove dirt and grease. When it had been immersed in hot water to facilitate blood flow and dried, the ball of the finger was firmly and sharply punctured with a Hagedorn needle. Very gentle pressure caused the blood to collect as a drop, which was allowed to fall on a circle of no. 3 I Whatman filter-paper. Each drop was collected separately.

Two experimental facts make it possible to estimate plasma cholinesterase accurately, using blood samples collected in this way. (I) Butyrylcholine is hydrolysed very rapidly by plasma or serum cholinesterase. The true cholinesterase, which is present in the erythrocytes, hydrolyses this substrate at a negligible rate; hence it is possible to estimate the plasma enzyme quite accurately in the presence of the true 
cholinesterase of the erythrocytes. (2) When a known volume of blood is allowed to spread on filter-paper, the area of the stain formed is, over the normal range of red-cell content, proportional to the amount of plasma in the whole blood. Thus if a disk of standard area is cut out from the stain, the volume of paper will always contain the same volume of plasma irrespective of the haematocrit of the specimen.

Analyses were carried out upon two disks cut from separate stains, each stain being formed as described above from separate drops. Each disk, 0.5 in. in diameter was punched out by a specially constructed punch. The technique of analysis was similar to that described by Callaway, Davies \& Rutland (195I) modified, in that butyrylcholine $(0.03 \mathrm{M})$ was used as substrate in place of acetylcholine and that the reaction mixture was added to the specimen on filter-paper rather than to wet blood.

In this paper, the activity of pseudo-cholinesterase is expressed as the volume of carbon dioxide, in $\mu \mathrm{l}$., produced in $30 \mathrm{~min}$ from the blood on two 0.5 in. disks of no. 31 Whatman filter-paper, using $0.03 \mathrm{M}$-butyrylcholine as substrate.

The nature of the population examined. Three hundred and forty-five males from three districts in England have been examined. They were distributed as follows: 86 youths all in their $17^{\text {th }}$ year, from Kingston, Surrey; I14 youths also in their 17 th year from Salford; and 145 adults employed in a wide range of industries at Slough.

Each individual was carefully examined clinically and his general health carefully assessed. Body-weight was also recorded.

\section{RESULTS}

The results obtained demonstrated a marked positive relationship between body fat and pseudo-cholinesterase. The mean pseudo-cholinesterase level in the 345 individuals examined was IOI.O units (S.D. $=23 \cdot 3$ ). The mean fat measurement was $46 \cdot 5 \mathrm{~mm}$ $($ S.D. $=17 \cdot 3$ ). The total correlation coefficient was 0.26 (Fisher's $(1946) z=0.2661 \pm$ 0.0539 ) which is highly significant. This relationship holds in each subgroup (see Table I).

Table I. Relationship between surface fat and plasma cholinesterase in 345 males from three districts in England. Total correlation coefficients and partial coefficients eliminating body-weight, with appropriate $\mathrm{z}$ tests

\begin{tabular}{|c|c|c|c|c|c|c|c|}
\hline \multirow[b]{2}{*}{ Sample } & \multirow[b]{2}{*}{$\begin{array}{l}\text { No. of } \\
\text { pairs }\end{array}$} & \multicolumn{3}{|c|}{ Total } & \multicolumn{3}{|c|}{ Partial (eliminating body-weight) } \\
\hline & & $r$ & $z$ & Odds against & $\boldsymbol{r}$ & $z$ & Odds against \\
\hline Slough & I 45 & 0.21 & $0.2132 \pm 0$. & $x: 92$ & 0.14 & $0.1409 \pm 0.0843$ & \\
\hline ind & 114 & 0.33 & $0.3428 \pm 0 . c$ & $1: 3300$ & 0.31 & $0.3206 \pm 0.09$ & $1: 1200$ \\
\hline Kingston & 86 & $0.2 \mathrm{I}$ & $0.2132 \pm 0.1095$ & I : I9 & 0.18 & $0.1820 \pm 0.1105$ & I : 9 \\
\hline Combined & 345 & 0.26 & $0.2661 \pm 0.0539$ & I : I 250,000 & 0.21 & $0.2132 \pm 0.0539$ & $1: 12,000$ \\
\hline
\end{tabular}

Partial coefficients eliminating body-weight are shown in Table $\mathrm{I}$ for each subgroup and also for the combined groups. A drop in the value of the partial as compared with the total correlation coefficients occurs when body-weight is eliminated. Neither the total nor the partial correlation coefficients differ significantly amongst themselves, hence the combination of all three subgroups to give an overall assessment of the relationship between fat and pseudo-cholinesterase is justified. 
Additional information concerning the Slough group was made available to us by Dr E. R. Bransby, who was simultaneously investigating diets and energy expenditure of the same subjects. He kindly provided us with data about the calorie intake and the nature of the daily work of these individuals. We have therefore examined the influence of calorie intake and energy expenditure in relation to the fat-pseudo-cholinesterase relationship demonstrated.

The partial correlation coefficient, eliminating calorie intake, was 0.2103 compared with the total correlation coefficient of 0.2143 . Thus, if the data obtained from the Slough subgroup may be assumed to be typical, it is unlikely that the level of calorie intake influences the fat-pseudo-cholinesterase relationship of men in metabolic equilibrium.

The energy expenditure based upon the type of work performed was graded according to an assessment made by $\mathrm{H}$. M. Medical Inspector of Factories. The grading was: light, light medium, medium, light heavy and heavy. These subsidiary groups however were too small statistically, and too inadequate to justify the expression of any opinion concerning the relationship of energy expenditure to the fat-pseudocholinesterase relationship.

\section{DISCUSSION}

A highly significant correlation has been shown to exist between surface fat and pseudo-cholinesterase in a large group of healthy British males drawn from various parts of the country and from different age and social groups. The survey did not include females, so no information is available concerning this correlation in women. There is, however, no a priori reason why such a relationship should not exist amongst women as well as men. The relationship was consistent in each of the three subgroups studied. It would appear to be influenced by body-weight but, on the limited evidence provided by the Slough subgroup, not in any way dependent upon calorie intake. Hutchinson et al. (1951) have produced evidence which in the words of the authors 'seems to leave no doubt that an insufficiency of Calories lowers the $\mathrm{P}-,, \ldots$, cholinesterase in the serum of man'. They also pointed out that the rise in pseudo-cholinesterase level was not related to the increased consumption of any major dietary constituents, but rather to the gradual gain in weight and well-being brought about by the better diet. During this period there must have undoubtedly been an increase in body fat and if this was in fact so, the findings of Hutchinson et al. may well be explained in terms of the fat-pseudo-cholinesterase correlation.

This relationship between fat and pseudo-cholinesterase is supported by a number of references in the literature. Thus, Hawkins \& Nishikawara (195I) showed that in rats on hypolipotrophic diets, the level of pseudo-cholinesterase rose both in the liver and plasma, and fell again when the dietary defect was made good. This finding suggests a linkage between the pseudo-cholinesterase and the metabolism of fat, a process in which the liver is known to play an important part. Conditions that impair the metabolism of carbohydrate may lead to greater demands upon fat. For example, Tuba \& Hoare (1949) have shown that the development of alloxan diabetes in rats is accompanied by a transient lipaemia which disappears in about a week and by 


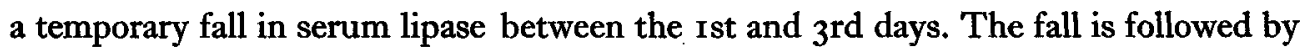
a persistent increase of $40-50 \%$. If pseudo-cholinesterase is associated with fat metabolism a rise in level should be found under these conditions. Antopol, Tuchman \& Schifrin (1937) have in fact found a raised pseudo-cholinesterase in man in diabetes, an observation confirmed by Faber (1943) and by Cristol, Passouant, Benezch \& Dutarte (1946); Saviano, Balbi, \& De Franciscis (1948) have made a similar observation in dogs suffering from alloxan diabetes.

\section{SUMMARY}

I. Measurements of surface fat and plasma cholinesterase have been made upon 345 males.

2. Surface fat was measured as skinfold thickness at five sites. Plasma cholinesterase was estimated from samples of blood collected upon filter-paper.

3. A highly significant positive correlation was found between the surface fat and plasma cholinesterase for each of the groups tested.

4. Body-weight only slightly influenced the relationship, which on the limited evidence available was not in any way affected by calorie intake.

We wish to record our appreciation of the help given us by Dr J. L. Burn, Medical Officer, Salford, Dr J. W. Storkey, Medical Officer, Kingston, and Dr A. A. Eagger, Director of Slough Industrial Health Service, Slough, and to their colleagues and administrative staff who arranged the necessary appointments for the examination of our subjects.

We also wish to thank Dr H. E. Magee of the Ministry of Health for his continued interest in this work.

Our great thanks are also due to Mr S. Peto of the Microbiological Research Department, Ministry of Supply, for help and advice in the statistical treatment of our results. We are also indebted to Mrs Margaret James for much careful technical assistance.

Finally, one of us (D.R.D.) wishes to thank the Chief Scientist, the Ministry of Supply, for permission to publish this paper.

\section{REFERENCES}

Antopol, W., Tuchman, L. \& Schifrin, A. (I937). Proc. Soc. exp. Biol., N.Y., 36, 46.

Berry, W. T. C. \& Cowin, P. J. (195I). Med. Offr, 26 May.

Brožek, J. \& Keys, A. (1950-1). Nutr. Abstr. Rev. 20, 247.

Callaway, S., Davies, D. R. \& Rutland, J. P. (195 I). Brit. med. F. ii, 81 2.

Cristol, P., Passouant, C., Benezch, C. \& Dutarte, J. (r946). Pr. méd. 40, 557. Quoted by Saviano, Balbi \& De Franciscis, 1948.

Edwards, D. A. W. (1950). Clin. Sci. 9, 259.

Faber, M. (1943). Acta med. scand. Ir4, 59.

Fisher, R. A. (1946). Statistical Methods for Research Workers, roth ed. London: Oliver and Boyd.

Hawkins, R. D. \& Nishikawara, M. T. (I95I). Biochem. F. 48, 276.

Hutchinson, A. O., McCance, R. A. \& Widdowson, E. M. (I95r). Spec. Rep. Ser. med. Res. Coun., Lond., no. 275, p. 216.

Saviano, M., Balbi, R. \& De Franciscis, P. (1948). Boll. Soc. ital. Biol, sper, 24, 1353.

Tuba, J. \& Hoare, R. (1949). Science, 110, 168. 